\title{
Determination of biomass burning tracers in air samples by GC/MS
}

\author{
Katarzyna Janoszka ${ }^{1, *}$ \\ ${ }^{1}$ Central Laboratory, Institute of Environmental Engineering Polish Academy of Science, \\ M. Skłodowskiej-Curie 34 street, 41-819 Zabrze, Poland
}

\begin{abstract}
Levoglucosan (LG) as a main cellulose burning product at $300^{\circ} \mathrm{C}$ is a biomass burning tracer. LG characterize by relatively high molar mass and it is sorbed by particulate matter. In the study of air pollution monitoring LG is mainly analyzed in particulate matter, $\mathrm{PM}_{1}$ and $\mathrm{PM}_{2,5}$. The tracer create relatively high $\mathrm{O}-\mathrm{H} \cdots \mathrm{O}$ bond and weaker $\mathrm{C}-\mathrm{H} \cdots \mathrm{O}$ bond. Due to the hydrogen bond, LG dissolves very well in water. Analytical procedure of LG determination include: extraction, derivatization and analysis by gas chromatography coupled with mass spectrometry detector. In water samples levoglucosan is determined by liquid chromatography. The paper presents a methodology for particulate matter samples determination their analysis by gas chromatography coupled with a mass spectrometry detector. Determination of LG content in particulate matter was performed according to an analytical method based on simultaneous pyridine extraction and derivatization using N,O-bis (trimethylsilyl) trifluoroacetamide and trimethylchlorosilane mixture (BSTFA: TMCS, 99: 1).
\end{abstract}

\section{Introduction}

In the twenty first century more effort is put on finding an alternative sources of energy such as biomass burning. Biomass is an organic matter mostly referred to plant-based materials. Biomass combustion in fireplaces, residential, campfires and wildfires emits wood smoke which is a main source of soot, particulate matter (PM), free radicals, irritants and other chemicals which can be toxic or mutagenic [1-5]. The atmospheric aerosol formed can scatter or absorb incoming solar radiation, change visibility impairments and modify cloud formation processes [6-9].

Wood biomass is mainly consist of cellulose (40-50\% of dry weight of wood, d.w.w) as well as hemicellulose (20-30\% of d.w.w.), lignins (20-30\% of d.w.w.) and additional components. The exact composition can differ depending on environmental aspects, type of tree (softwood or hardwood) and its genus. At temperature below $300^{\circ} \mathrm{C}$ cellulose depolymerize, water is eliminated, fragmentation and oxidation lead to formation of char. At the temperature above $300^{\circ} \mathrm{C}$ cellulose undergo pyrolysis involving bond cleavage, fission and disproportionation leading meanly to 1,6-anhydride of glucose, polar

\footnotetext{
*Corresponding author: katarzyna.janoszka@ipis.zabrze.pl
} 
dehydrated glucose with a ketal functional group - levoglucosan, (LG; 1,6-anhydro- $\beta$-Dglucopyranose) [3-5,10-12]

Levoglucosan is thermal decomposition product form during thermal catalytic processing from plant biomass (cellulosic material) [13]. LG in a solid state has a crystal structure, it contain relatively strong $\mathrm{O}-\mathrm{H} \cdots \mathrm{O}$ hydrogen bonds together with weaker interaction in $\mathrm{C}-\mathrm{H} \cdots \mathrm{O}$ and because of the strong $\mathrm{H}$ bonds its molecules is linked into finite chain [14].

During biomass combustion there are also find isomers of levoglucosan, other monosaccharide derivatives like galactosan (GA) and mannosan (MN) (Fig. 1) but in minority because they are products of hemicellulose burning $[5,10,11,15]$. The ratio of levoglucosan to mannosan and/or galactosan can lead to the type of biomass burned by "chemical fingerprint" [16-19]. The marker that allow us to define biomass burning source should be a product of its degradation, emitted in majority at high concentration. It must be stable in environment and long-range transportation as well as easily detectable $[1-3,10,20$ 22].

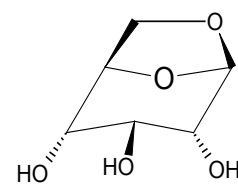

Levoglucosan

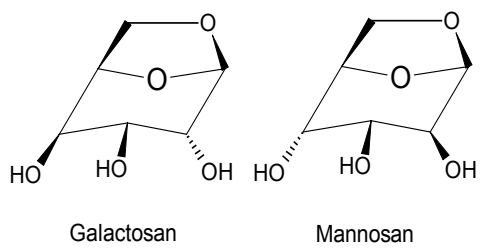

Fig. 1. Chemical structure of levoglucosan, galactosan and mannosan.

Levoglucosan is considered to be a biomass combustion marker because it meets the above requirements and as so it is determine. In atmospheric aerosol it shows resistance to photochemical oxidation, acid catalyzed hydrolysis and diagenesis in sediments. Because of its stability the same samples (e.g.: urban dust samples) can be determine in different laboratory conditions and use for comparative study [15,23]. LG is mainly entrapped in charcoal, ash and in urban dust and is associated with ultrafine particulate matter $[10,15]$.

Gas chromatography coupled with mass spectrometry detector (GC/MS) is usually use to determine the LG in wood smoke, PM, ashes, soil and sediment samples [1-19,23] but other techniques as high performance liquid chromatography with aerosol charge detection (HPLC-ACD), high-performance anion-exchange chromatography with pulsed amperometric detection (HPAEC-PAD) or capillary electrophoresis with pulsed amperometric detection (CE-PAD) are also applied. The GC determination of levoglucosan consist of extraction, derivatization - mainly based on silylation giving trimethylsilyl ether derivative to reduce its polarity, same increase its volatility and analysis. The fragment ions used for identification was $m / z$ 204, 217, 333 for electron impact ionization (EI). When levoglucosan was directly injected to GC/MS the results are unsatisfactory, chromatographic behavior was poor and response was low $[1,10]$.

Extraction could be conducted in Soxhlet apparatus [6,24] or by pressurized fluid extraction with an accelerated solvent extraction (PFE ASE) [6]. However the most popular extraction technique is extraction in ultrasonic bath in different solvents or its mixture $[1,2,5,11,18,25-28]$.

As for derivatizating agent different silylating reagents are used, like N,Obis(trimethylsilyl)trifluoroacetamide (BSTFA), trimethylchlorosilane (TMCS), trimethylsilyl iodide (TMSI), trimethylsilylimidazole (TSIM) as well as N-methyl-N(trimethylsilyl) trifluoroacetamide (MSTFA) in the presence or absence of solvent, like this use for extraction or e.g.: pyridine or DTE (1,4-dithioerythritol). When silylating agent or 
its mixture is added to prepared sample extract the mixture is allowed to react for specific time at adequate temperature.

\section{Experimental}

\subsection{Chemicals}

Levoglucosan (1,6-anhydro- $\beta$-D-glucose)was obtained from Sigma Aldrich Fine Chemicals with a stated purity of $99 \%$. N,O-bis(trimethylsilyl)trifluoroacetamide (BSTFA) with trimethylchlorosilane (TMCS) (BSTFA:TMCS, 99:1) were obtained from Supelco. Pyridine, pure for analysis, were obtained from Avantor Performance Materials Poland S.A. (formerly POCH S.A.).

\subsection{Sample collection}

Samples of $\mathrm{PM}_{10}$ were collected on $47 \mathrm{~mm}$ Whatman QMA quartz filters at a 24-h cycle with the use of a low flow sampler with separating head $\mathrm{PM}_{10}$ Autoservice PNS3D15/LVS3d with a stabilized flow of $2.3 \mathrm{~m}^{3} / \mathrm{h}$. Aerosol samples were collected from March 2016 to April 2017 in Krynica Zdroj in the health resort - climatological station IMGW-PIB department in Cracow ( $\Phi=49^{\circ} 24^{\prime} 28^{\prime \prime}, \lambda=20^{\circ} 57^{\prime} 39^{\prime \prime}, \mathrm{h}=582 \mathrm{~m}$ above sea level), near the border with Slovakia. The samples were sealed and transported to the laboratory at low temperature.

\subsection{Extraction and Analysis}

The quartz filters were cut into two parts and one half was placed in a reaction vial. Two milliliters of pyridine and $50 \mu \mathrm{l}$ derivatizating mixture of N,Obis(trimethylsilyl)trifluoroacetamide (BSTFA) and trimethylchlorosilane (TMCS) (BSTFA:TMCS, 99:1) were added in order to form silyl derivatives. The vial was sealed, vigorously shaken for $1 \mathrm{~min}$. and put into an oven for $30 \mathrm{~min}$. at $40^{\circ} \mathrm{C}$ in order to react. The $1 \mathrm{ml}$ of extract were filtered through $0.22 \mu \mathrm{m}$ syringe filter and analyzed by a Shimadzu GC-2010 gas chromatograph coupled with mass spectrometry detector (GC/MS) equipped with a $30 \mathrm{~m}$; $0.25 \mathrm{~mm}$ i.d.; $0.25 \mu \mathrm{m}$ film thickness HP-5MS capillary column.

\section{Results and Discussion}

During method development several reaction temperatures and reaction length were tested. Temperature at which reaction efficiency were tested was in a range from $40^{\circ} \mathrm{C}$ to $70^{\circ} \mathrm{C}$ (Fig.2.). Temperature increase caused the signal from levoglucosan derivative to decrease. At higher temperatures levoglucosan probably isomerizes and the reaction efficiency diminishes. Therefore reaction temperature was set for $40^{\circ} \mathrm{C}$. 


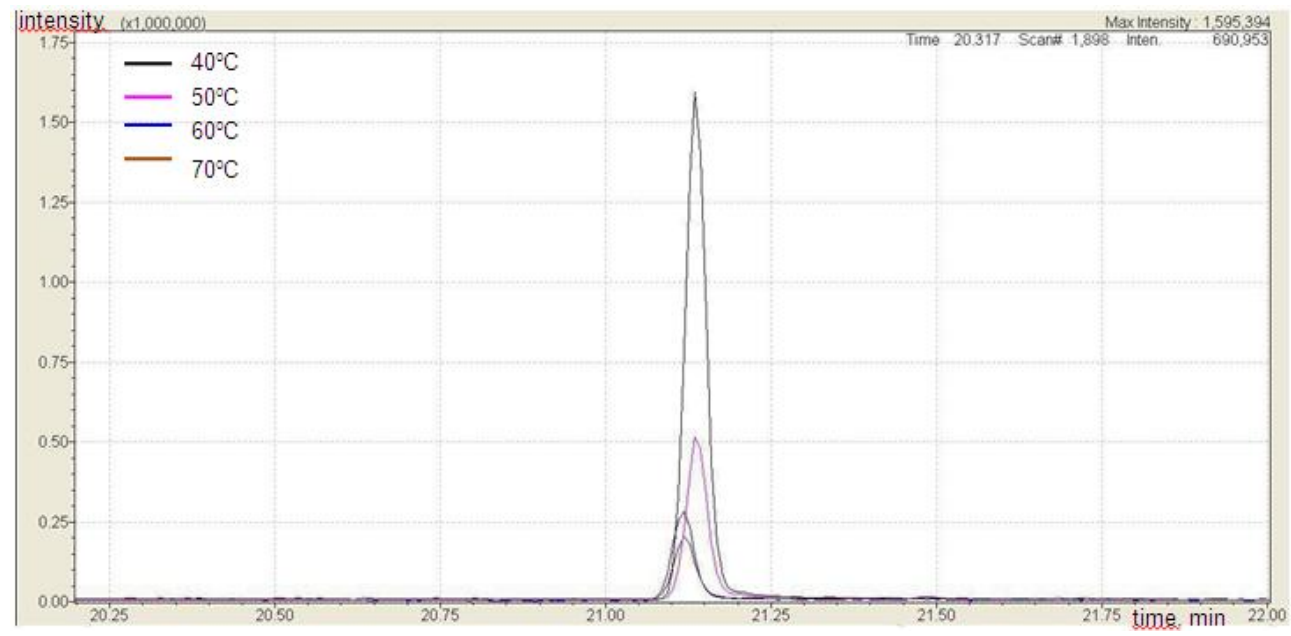

Fig. 2. Comparison of reaction temperatures.

The reaction length was also tested and there is no relevant differences between 30 minutes, 1 hour and 3 hours (Fig.3.). Because of that fact the reaction time was set for $30 \mathrm{~min}$.

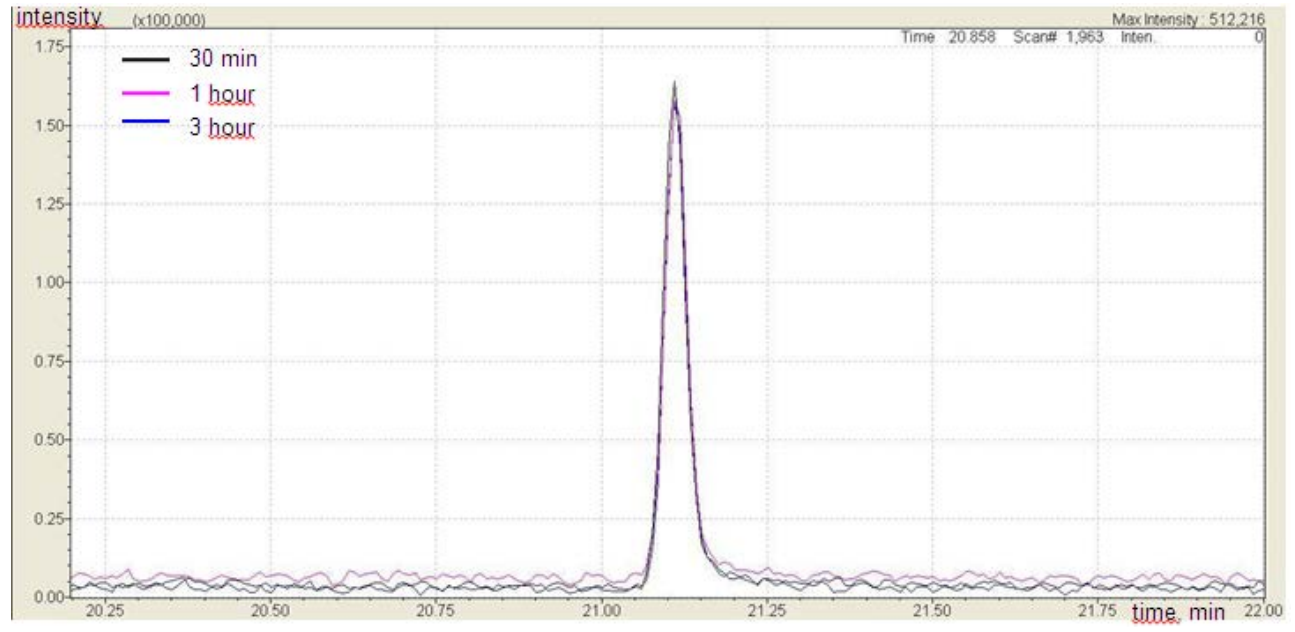

Fig. 3. Comparison of reaction length.

The set of 10 blank samples was analyzed. Blank filters were spiked with $1.5 \mu \mathrm{g}$ of levoglucosan and the recovery was $95 \%$. Precision - expressed as a relative standard deviation (RSD) - was equal 19\%. Due to non-linear apparatus response the calibration range was divided into four calibration ranges. Calibration was performed in four concentration ranges: $0.02-0.2 \mu \mathrm{g} / \mathrm{mL} ; 0.2-2.0 \mu \mathrm{g} / \mathrm{mL} ; 2.0-6.0 \mu \mathrm{g} / \mathrm{mL}$; and $5.0-35.0 \mu \mathrm{g} / \mathrm{mL}$. The detection limit (LOD) was estimated as the concentration visible in the chromatogram with a peak height at least three times the signal to noise ratio, which was found to be 0.008 $\mu \mathrm{g} / \mathrm{mL}$ and LOQ was expressed as 3 LOD amounts of $0.023 \mu \mathrm{g} / \mathrm{mL}$. This corresponds to $0.001 \mu \mathrm{g} / \mathrm{m}^{3}$ and $0.002 \mu \mathrm{g} / \mathrm{m}^{3}$, respectively.

The method was applied to real samples of $\mathrm{PM}_{10}$ from Krynica Zdroj. The results of the levoglucosan concentrations are plotted at Fig. 3. Mean LG concentration during measurement campaign was $0.51 \mu \mathrm{g} / \mathrm{m}^{3}$. The lowest $\mathrm{LG}$ concentration $0.01 \mu \mathrm{g} / \mathrm{m}^{3}$ were 
found in May (2016-05-23) and the highest concentration $3.15 \mu \mathrm{g} / \mathrm{m}^{3}$ in November (201611-24).

\section{Conclusions}

The method based on simultaneous extraction and derivatization of levoglucosan provide easy sample preparation and give low detection limit - $0.008 \mu \mathrm{g} / \mathrm{mL}$ and limit of quantification - $0.023 \mu \mathrm{g} / \mathrm{mL}$. Analysis of $\mathrm{PM}_{10}$ samples shows the presence of levoglucosan. $\mathrm{LG}$ concentrations ranged from 0.01 up to $3.15 \mu \mathrm{g} / \mathrm{m}^{3}$.

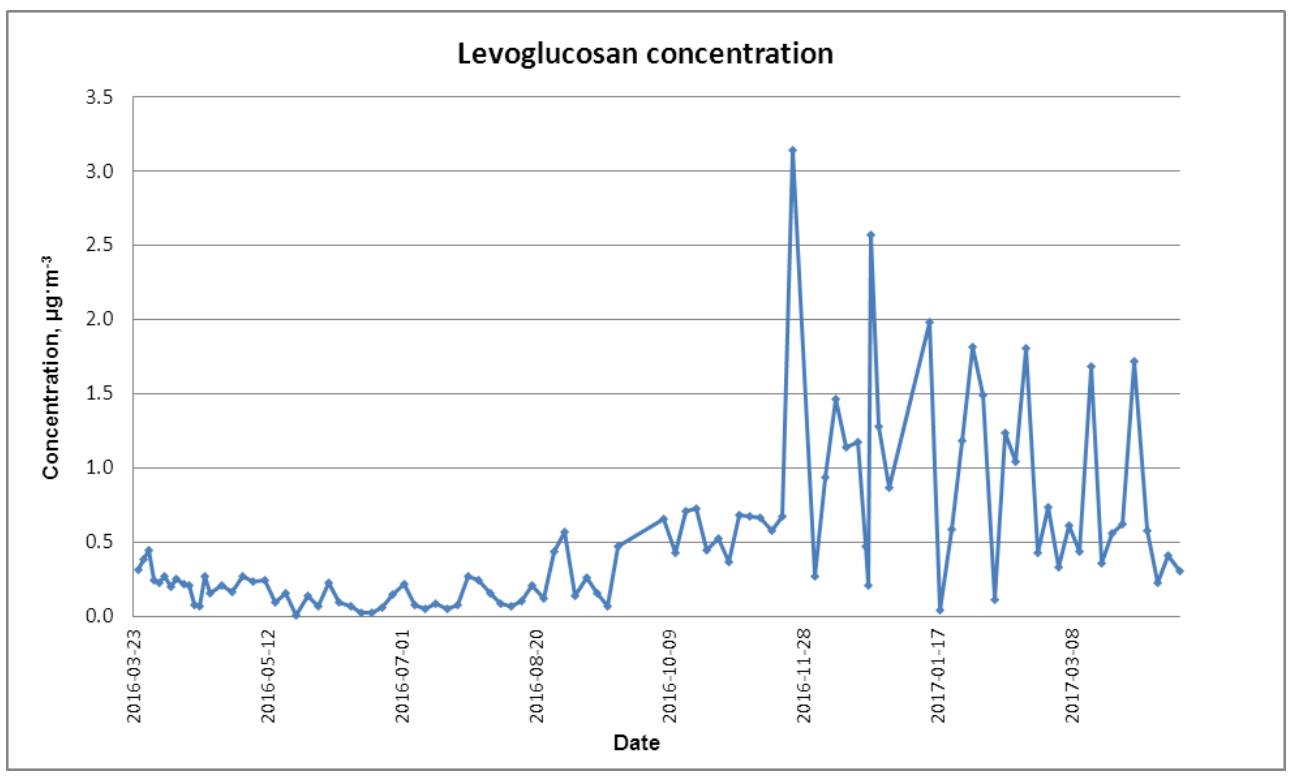

Fig. 4. Levoglucosan concentrations.

\section{References}

1. C.D. Simpson, R.L. Dills, B.S. Katz, D. A. Kalman, J. Air \& Waste Manage. Assoc., 54, 689-694 (2004)

2. O. Adetona, C.D. Simpson, G. Onstad, L.P. Naeher, Occup. Hyg.,57(8), 979-991 (2013)

3. B.R.T. Simoneit, J.J. Schauer, C.G. Nolte, D.R. Oros, V.O. Elias, M.P. Fraser, W.F. Rogge, G.R. Cass, Atmospheric Environment, 33, 173-182 (1999)

4. M.-S. Bae, J.Y. Lee, Y.-P. Kim, M.-H. Oak, J.-S. Shin,K.-Y. Lee, H. Lee, S.Y. Lee, YJ. Kim, Asian Journal of Atmospheric Environment, 6-1, 53-66 (2012)

5. D.R. Oros, B.R.T. Simoneit, Applied Geochemistry, 16, 1513-1544 (2001)

6. R.K. Larsen, M.M. Schantz, S.A. Wise, Aerosol Science and Technology, 40, 781-787 (2006)

7. G. Schkolnik, Y. Rudich, Anal Bioanal Chem, 385, 26-33 (2006)

8. S. Gao, D.D. Hegg, P.V. Hobbs, T.W. Kirchstetter, B.I. Magi, M. Sadilek, J. Geophys. Res., 108(D13), SAF 27-1-SAF 27-16 (2003)

9. B. Graham, O.L. Mayol-Bracero, P. Guyon, G.C. Roberts, S. Decesari, C.M. Facchini, P. Artaxo, W. Maenhaut, P. Koll, M.O. Andreae, J. Geophys. Res., 107(D20), LBA 141-LBA 14-16 (2002) 
10. V.O. Elias, B.R.T. Simoneit, R.C. Cordeiro, B. Turcq, Geochimica et Cosmochimica Acta, 65(2), 267-272 (2001)

11. M.R. Abas bin, D.R. Oros, B.R.T. Simoneit, Chemosphere, 55, 1089-1095 (2004)

12. L.-J. Kuo, B.E. Herbert, P. Louchouarn, Organic Geochemistry, 39, 1466-1478 (2008)

13. G.J. Kabo, Y.U. Paulechka, O.V. Voitkevich, A.V. Blokhin, E.N. Stepurko, S.V. Kohut, Y.V. Voznyi, J. Chem. Themodynamics, 85, 101-110 (2015)

14. Ĺ. Smrčok, M. Sládkovičová, V. Langer, C.C. Wilson, M. Koóš, ActaCrys. B62, 912918 (2006)

15. P. Louchouarn, L.-J. Kuo, T.L. Wade, M. Schantz, Atmospheric Environment, xxx, 1-7 (2009)

16. A. Otto, R. Gondokusumo, M.J. Simpson, Applied Geochemistry, 21, 166-183 (2006)

17. R.L. Cordell, M. Mazet, C. Dechoux, S.M.L. Hama, J. Staelens, J. Hofman, C. Stroobants, E. Roekens, G.P.A. Kos, E.P. Weijers, K.F.A. Frumau, P.T. Panteliadis Delaunay, K.P. Wyche, P.S.Monks, Atmospheric Environment, 141, 276-286 (2016)

18. R.L. Cordell, I.R. White, P.S. Monks, Anal Bioanal Chem, 406, 5283-5292 (2014)

19. D. Fabbi, C. Torri, B.R.T. Simoneit, L. Marynowski, A.I. Rushdi, M.J. Fabiańska, Atmospheric Environment, 43, 2286-2295 (2009)

20. M. Giannoni, T. Martellini, M. Del Bubba, A. Gambaro, R. Zangrando, M. Chiari, L. Lepri, A. Cincinelli, Environmental Pollution, 167, 7-15 (2012)

21. C.D. Garcia, G. Engling, P. Herckes, J.L. Jr. Collett, C.S. Henry, Environ. Sci. Technol., 39, 618-623 (2005)

22. B.Graham, O.L.Mayol-Bracero, P. Guyon, G.C. Roberts, S. Decesari, C.M. Facchini, P. Artaxo, W. Maenhaut, P.Koll, M.O. Andreae, J. Geophys. Res., 107(D20), LBA 141-LBA 14-16 (2002)

23. K.E. Yttri, J. Schnelle-Kreis, W. Maenhaut, G. Abbaszade, M. Claeys, Atmos. Meas. Tech. 8, 125-147 (2015)

24. E. Hedberg, C. Johansson, L. Johansson, E. Swietlicki, E. Brorstrom-Lunden, J. Air \& Waste Manage. Assoc., 56, 1669-1678 (2006)

25. C.-L. Hsu, C.-Y. Cheng, C.-T. Lee, W.-H. Ding, Talanta, 72, 199-205 (2007)

26. Z. Zdráhal, J. Oliveira, D. Vermaylen, M. Claeys, W. Maenhaut, Environ. Sci. Technol, 36, 747-753 (2002)

27. M. Mochida, K. Kawamura, P.Fu, T. Takemura, Atmospheric Environment, 44, 35113518 (2010)

28. T. Zhang, M. Claeys, H. Cachier, D. Shuping, W. Wang, W. Maenhaut, X. Liu, Atmospheric Environment, 42, 7013-7021 (2008) 